\title{
Transmetalation and Demetallization for Open-Oyster-Like Non-Ionic Cd(II) Macrocycles
}

Pei-Chen Zhao, ${ }^{\dagger}$ Fei-Fan Chang, ${ }^{\dagger}$ Fan-Da Feng, ${ }^{\dagger}$ and Wei Huang, ${ }^{* \dagger} *$

$\dagger$ State Key Laboratory of Coordination Chemistry, School of Chemistry and Chemical Engineering, Nanjing University, Nanjing, Jiangsu Province, 210093, P. R. China

$\$$ Shenzhen Research Institute of Nanjing University, Shenzhen, 518057, P. R. China

* Corresponding author' email address: whuang@nju.edu.cn 


\section{Supporting Information}

\section{Scheme SI1 Schematic illustration for the preparation of PDPA.}

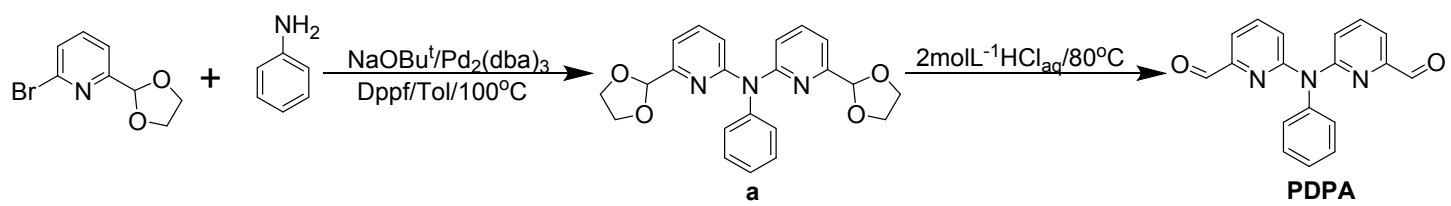

\section{Instruments}

${ }^{1} \mathrm{H}$ NMR spectra measurements were taken on Bruker AM 300 or 400 NMR spectrometer, using TMS $\left(\mathrm{SiMe}_{4}\right)$ as an internal reference at room temperature. Elemental analyses were measured with a PerkinElmer 1400C analyzer. IR spectra $\left(4000-500 \mathrm{~cm}^{-1}\right)$ were collected on a Nicolet FT-IR 170X spectrophotometer at $25{ }^{\circ} \mathrm{C}$ using $\mathrm{KBr}$ plates. UV-vis spectra were recorded with a Shimadzu UV-3150 double-beam spectrophotometer using a quartz glass cell with a path length of $10 \mathrm{~mm}$. Powder X-ray diffraction (PXRD) measurements were performed on a Philips X'pert MPD Pro X-ray diffractometer using $\mathrm{Cu} K \alpha$ radiation $(\lambda=0.15418 \mathrm{~nm})$, in which the X-ray tube was operated at $40 \mathrm{kV}$ and $40 \mathrm{~mA}$ at room temperature. Electrospray ionization mass spectra (ESI-MS) were recorded on a ThermoFisher Scientific LCQ Fleet mass spectrometer within the range 200-2000 amu.

\section{X-ray Data Collection and Structural Determination}

Single-crystal samples of three complexes were covered with glue and mounted on glass fibers and then used for data collection. Crystallographic data were collected on a Bruker SMART 1K CCD diffractometer, using graphite mono-chromated Mo K $\alpha$ radiation $(\lambda=0.71073 \AA)$. The crystal systems were determined by Laue symmetry and the space groups were assigned on the basis of systematic absences using XPREP. Absorption corrections were performed to all data and the structures were solved by direct methods and refined by full-matrix least-squares method on $F_{\mathrm{obs}}{ }^{2}$ by using the SHELXTL-PC software package. ${ }^{[1]}$ All non-H atoms were anisotropically refined and all hydrogen atoms were inserted in the calculated positions assigned fixed isotropic 
thermal parameters and allowed to ride on their respective parent atoms. In the case of complexes $S, S-\mathbf{1 a}$ and $R, R-\mathbf{1 b}$, it is found that the solvent molecules were highly disordered. Attempts to locate and refine the solvent peaks were unsuccessful. So contributions to scattering due to these solvent molecules were removed using the SQUEEZE routine of PLATON. The structures were then refined again using the data generated. The contents of the solvent region are not represented in the unit cell contents in these crystal data. The summary of the crystal data, experimental details and refinement results for three complexes is listed in Table 1, whereas bond distances and angles are given in Table 2.

\section{References}

[1] (a) G. M. Sheldrick, SHELXTL-2014. Program for structure solution; Universität of Göttingen: Göttingen, Germany, 2014. (b) G. M. Sheldrick, SHELXTL-2014. Program for structure refinement; Universität of Göttingen: Göttingen, Germany, 2014. 

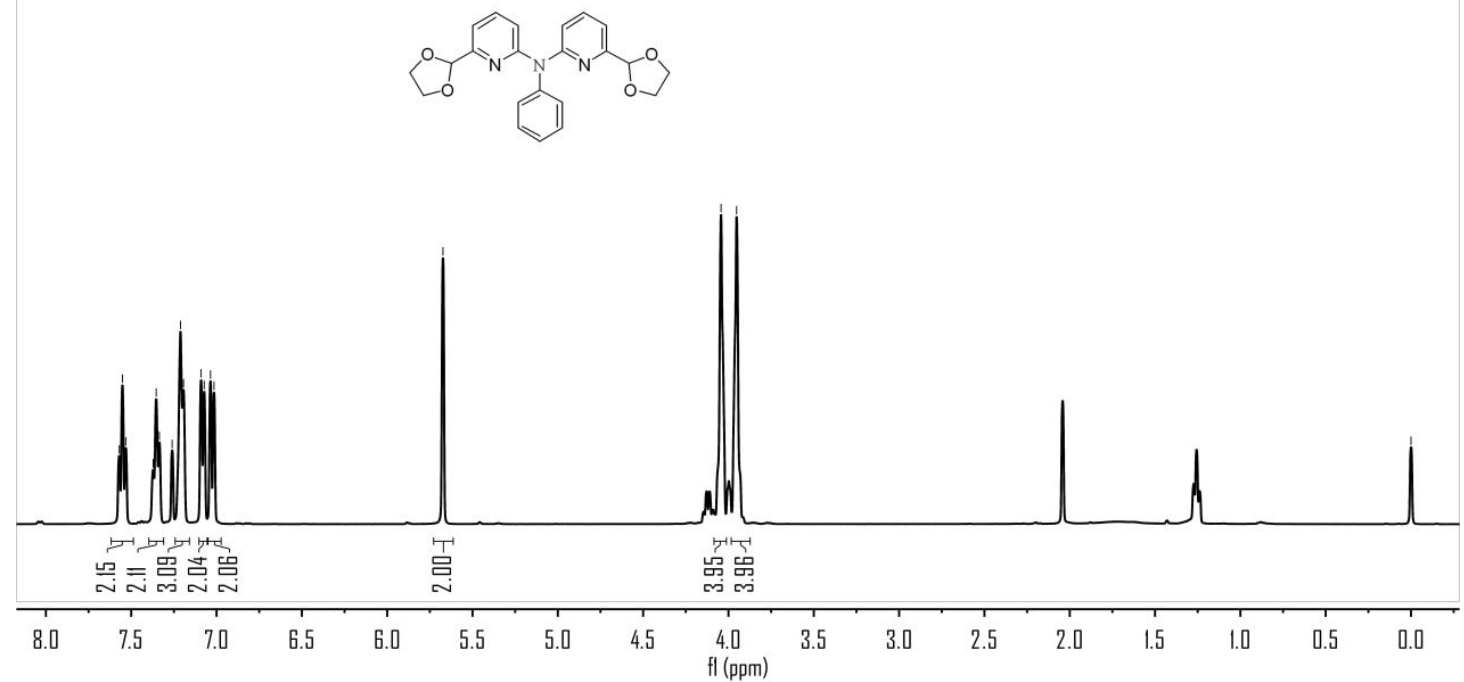

Figure SI1. ${ }^{1} \mathrm{H}$ NMR spectrum of $\mathbf{a}$ in $\mathrm{CDCl}_{3}$.

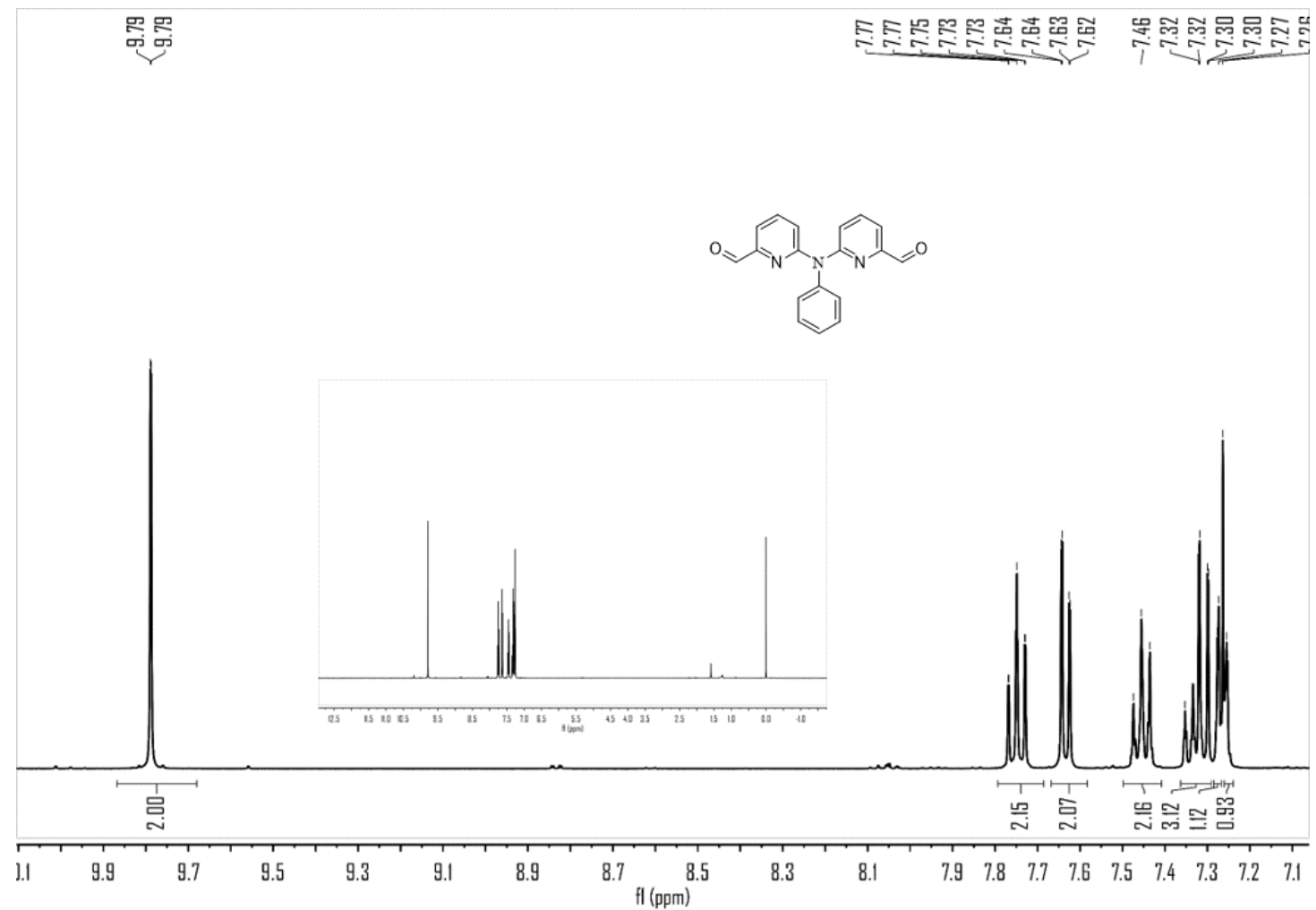

Figure SI2. ${ }^{1} \mathrm{H}$ NMR spectrum of PDPA in $\mathrm{CDCl}_{3}$. 


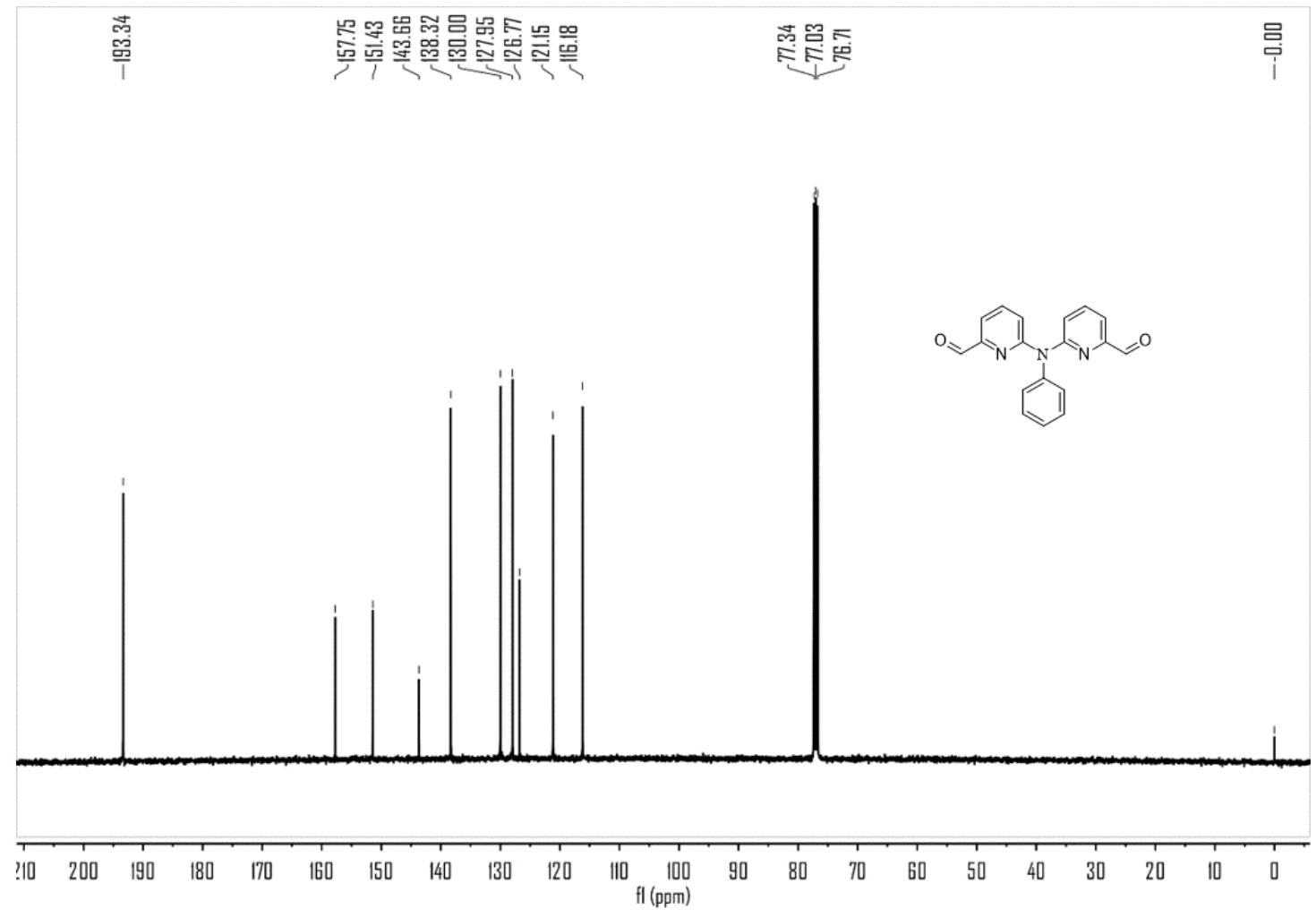

Figure SI3. ${ }^{13} \mathrm{C}$ NMR spectrum of PDPA in $\mathrm{CDCl}_{3}$.

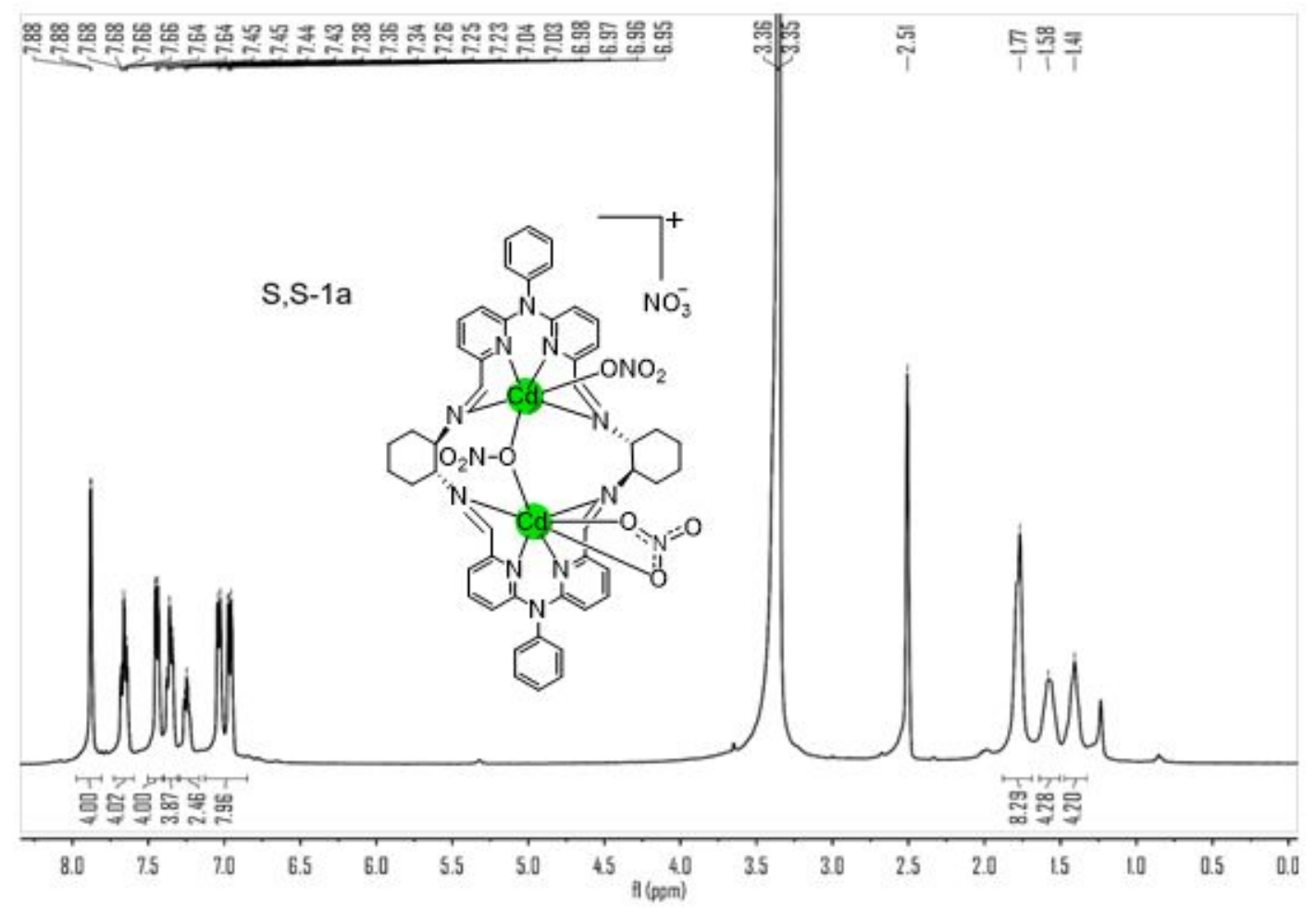

Figure SI4. ${ }^{1} \mathrm{H}$ NMR spectrum of Cd(II) complex $S, S-\mathbf{1 a}$ in DMSO- $d_{6}$. 


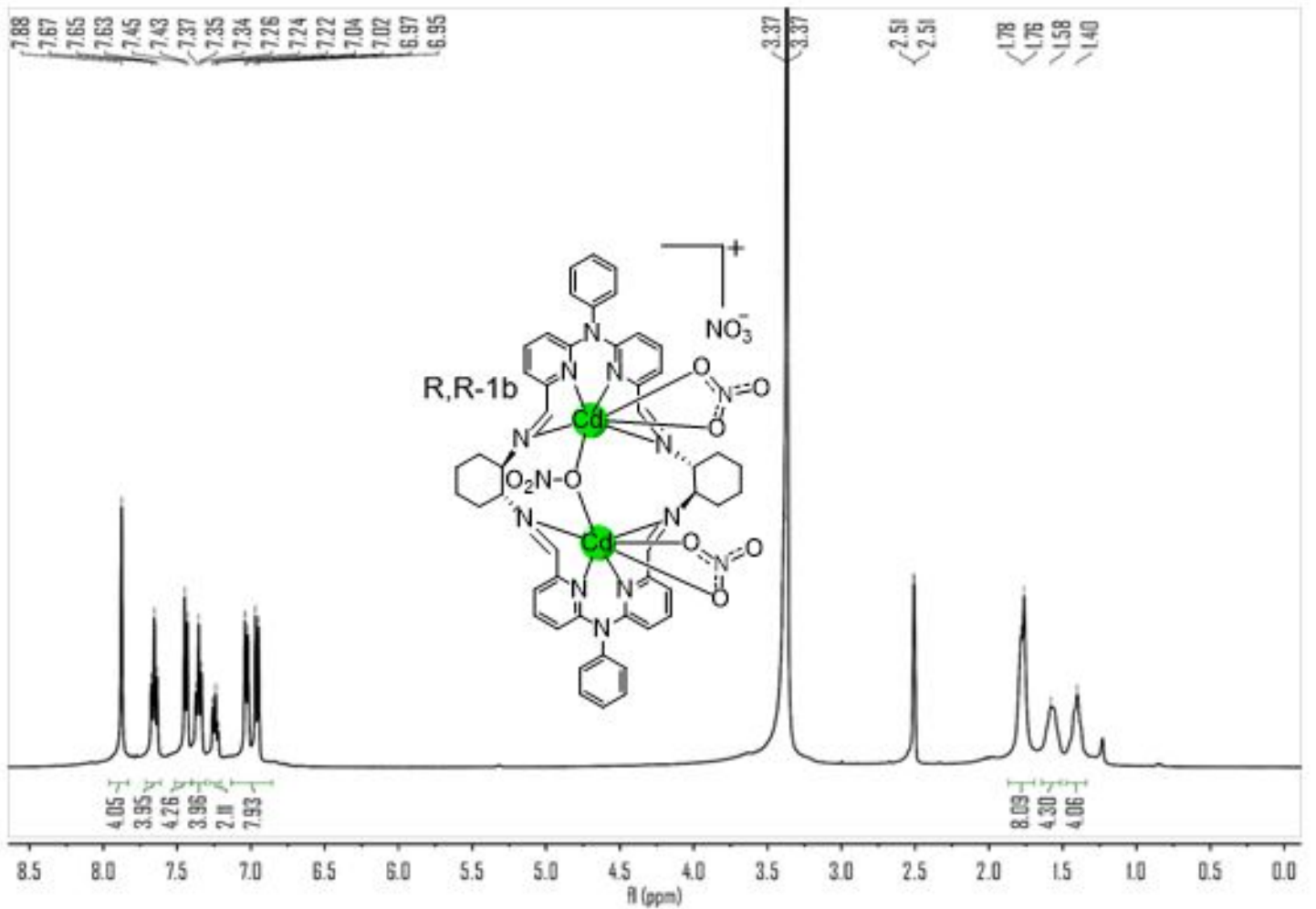

Figure SI5. ${ }^{1} \mathrm{H}$ NMR spectrum of Cd(II) complex $R, R-\mathbf{1 b}$ in DMSO- $d_{6}$.

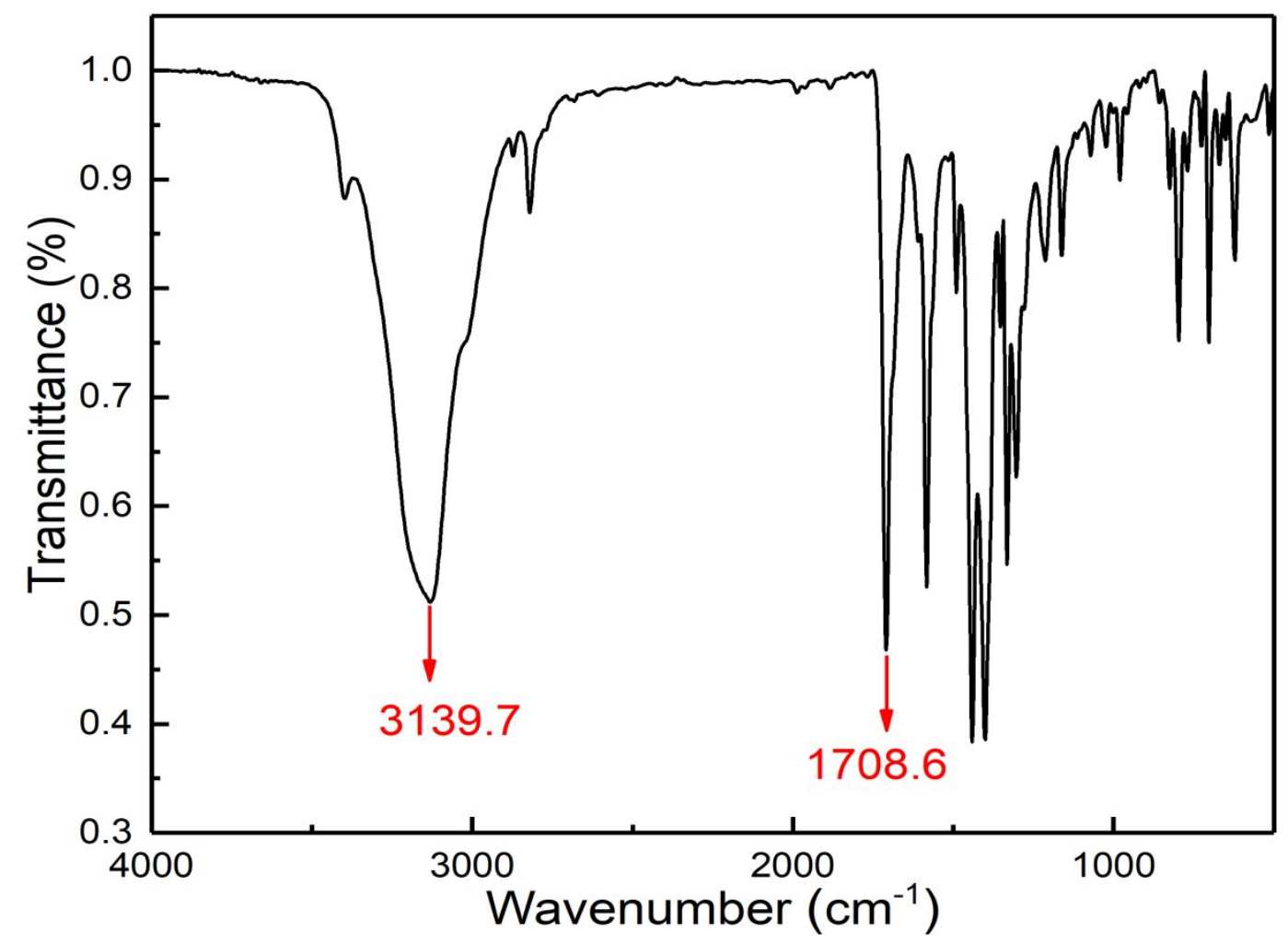

Figure SI6. FT-IR spectrum of DACH. 


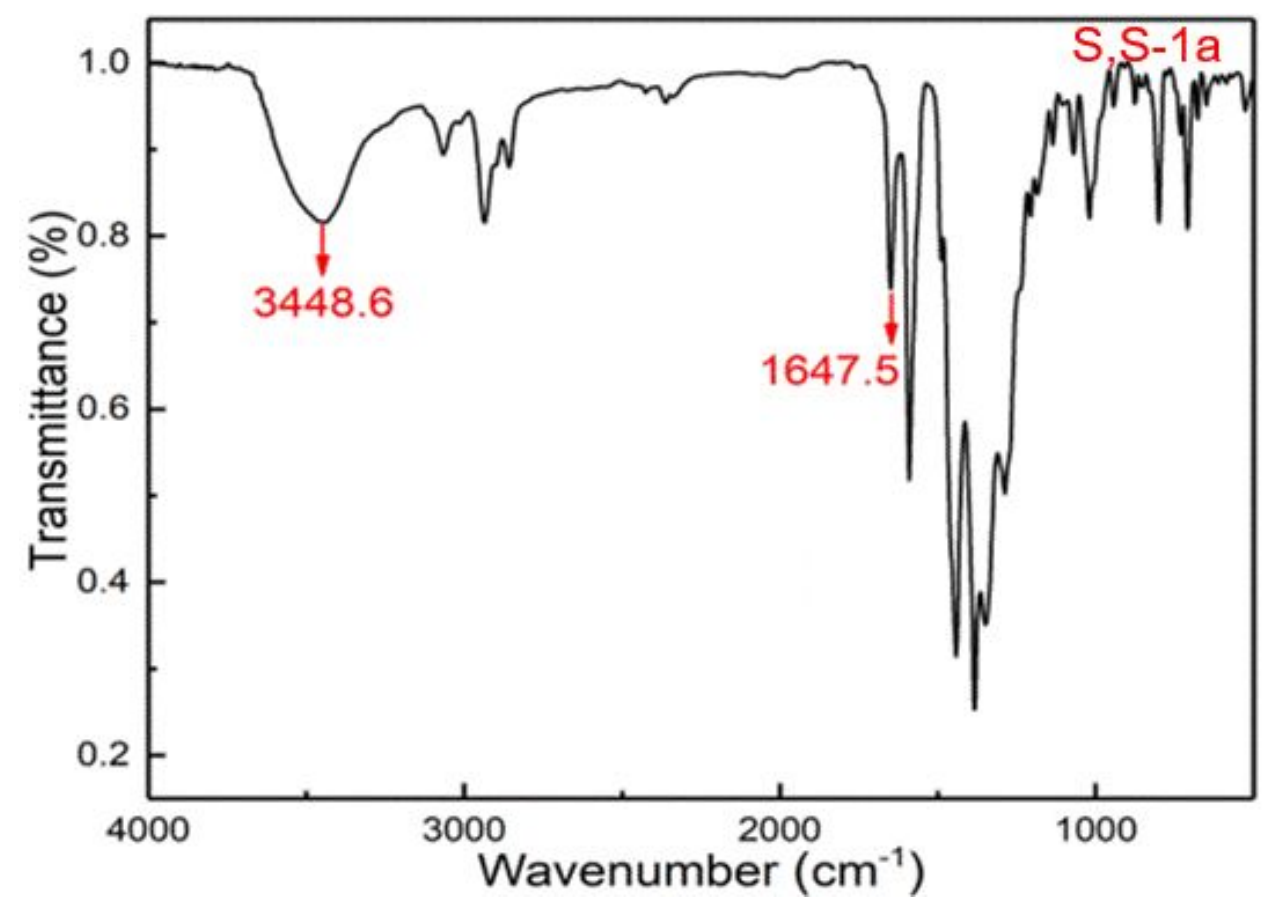

Figure SI7. FT-IR spectrum of Cd(II) complex $S, S-\mathbf{1 a}$.

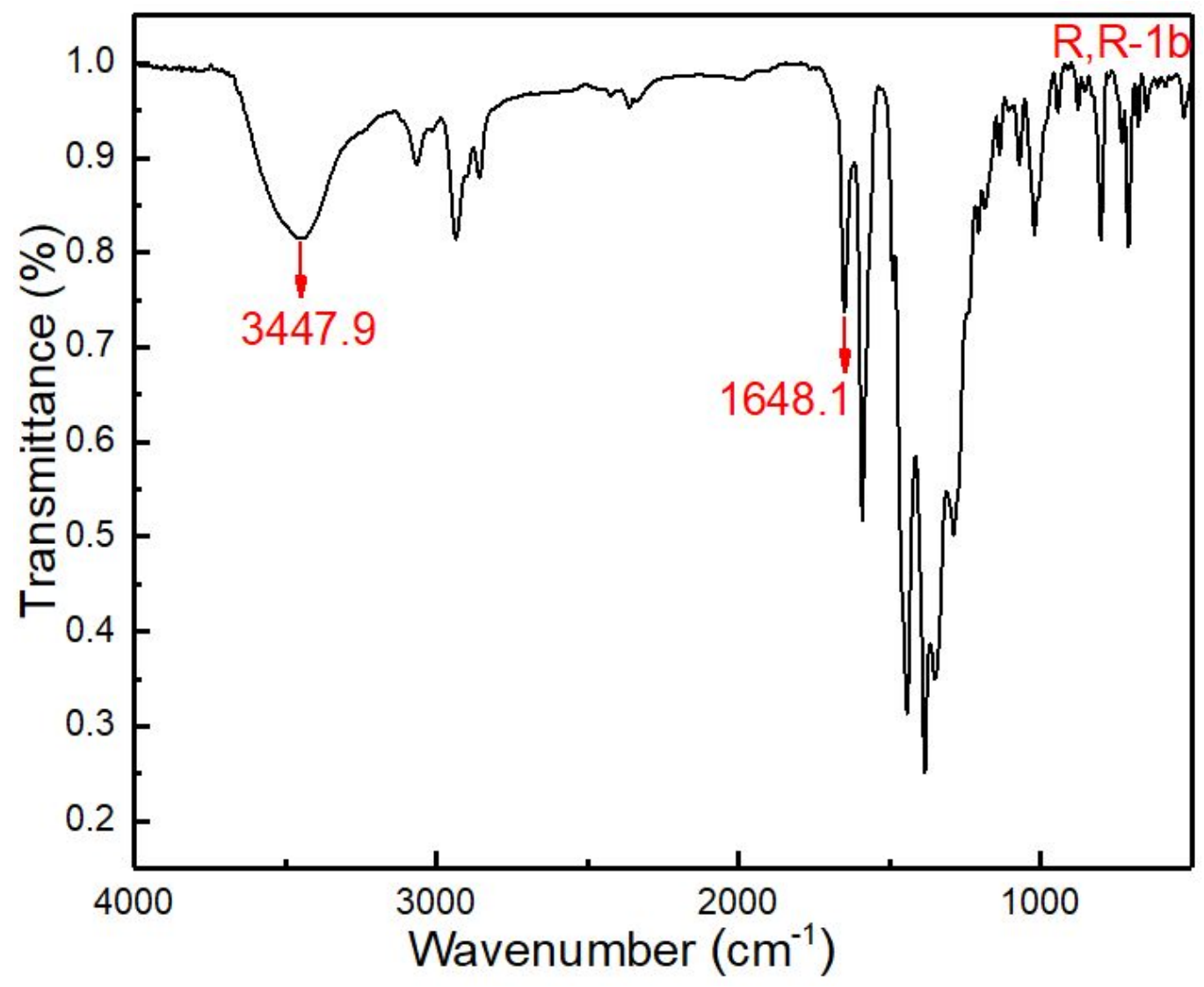

Figure SI8. FT-IR spectrum of Cd(II) complex $R, R-\mathbf{1 b}$. 


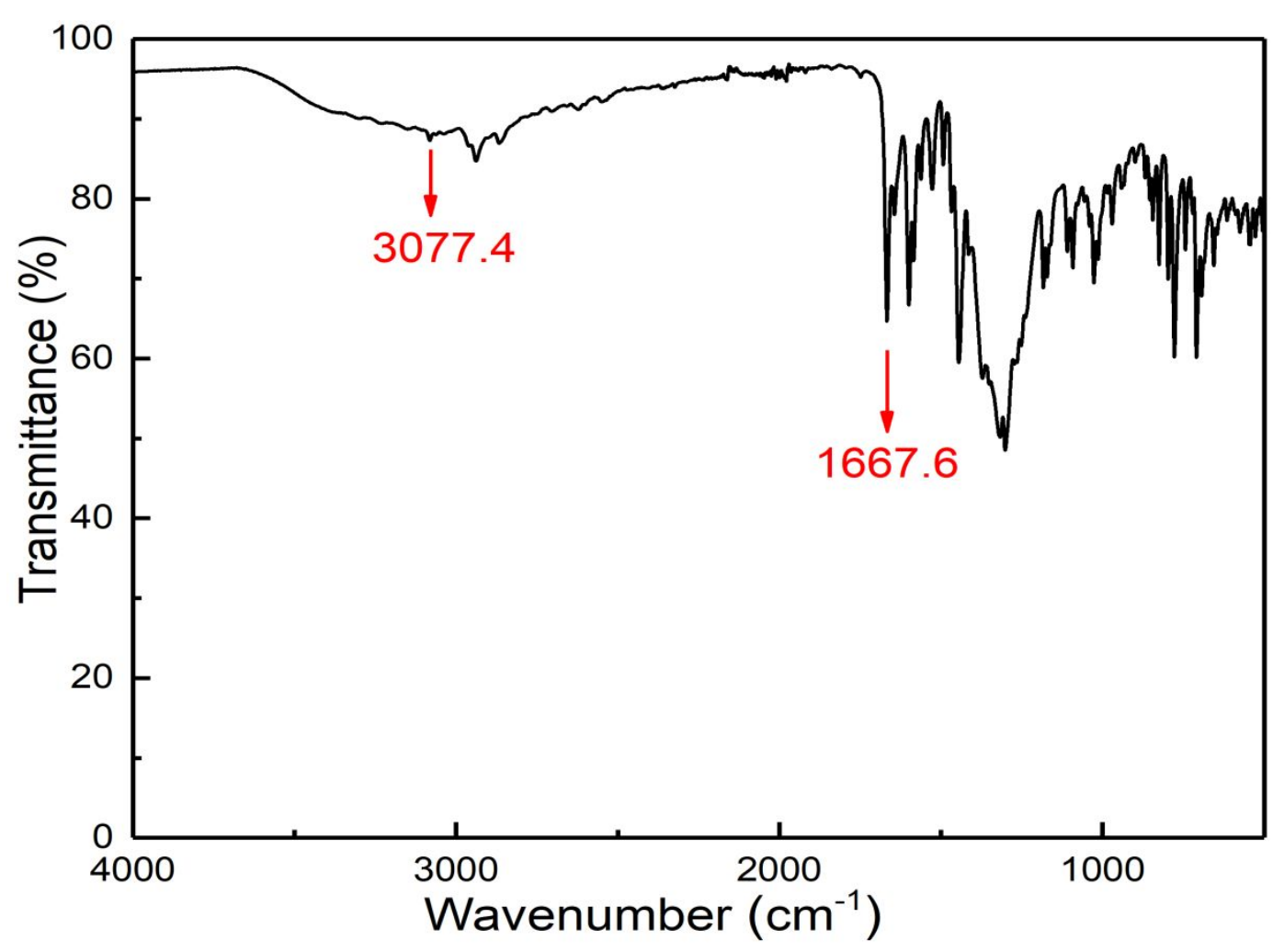

Figure SI9. FT-IR Spectrum of $\mathrm{Cu}(\mathrm{II})$ Complex $S, S-2$.

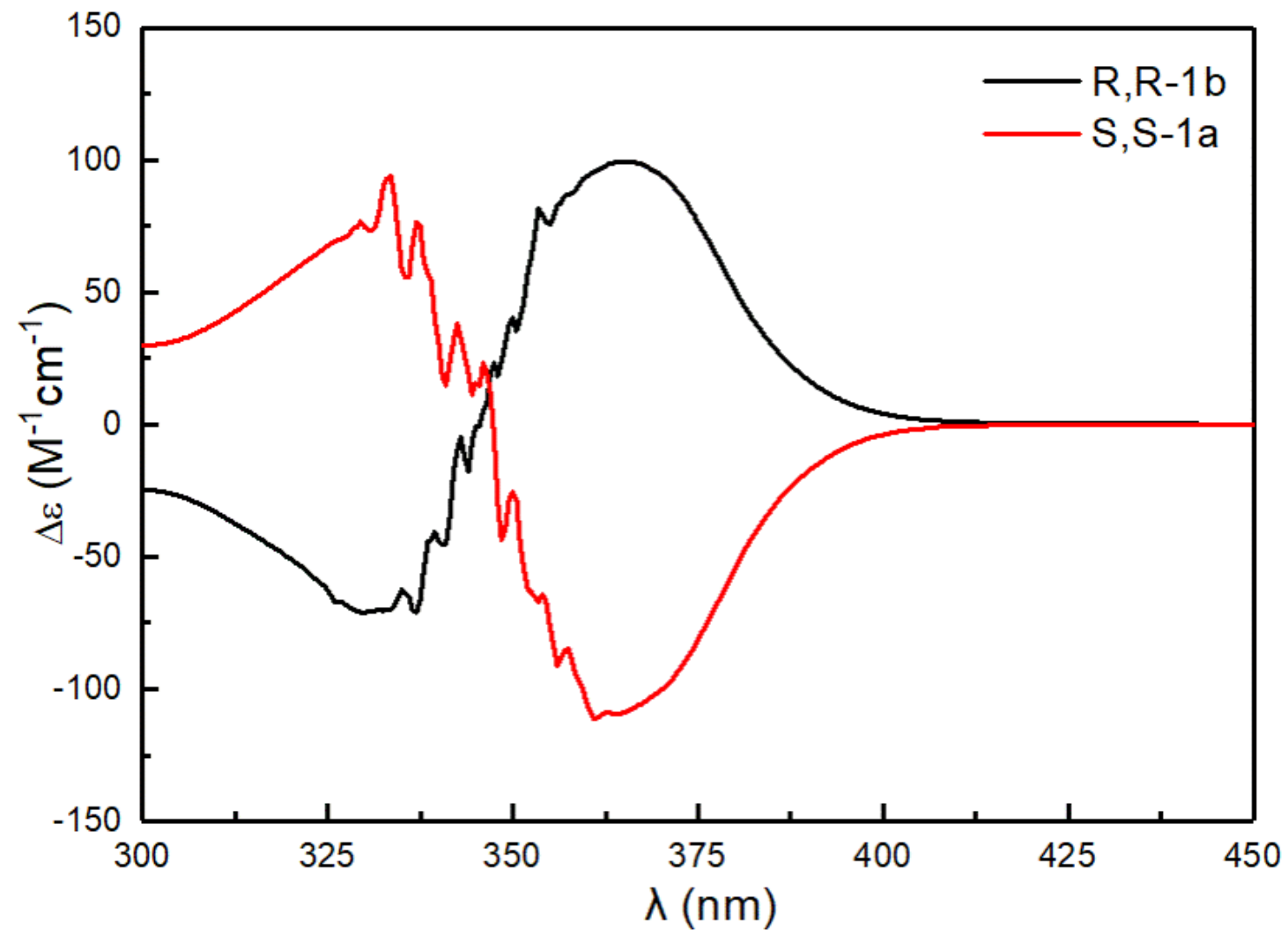

Figure SI10. CD Spectra of Cd(II) complexes $S, S-\mathbf{1 a}$ and $R, R-\mathbf{1 b}$ in $\mathrm{CH}_{3} \mathrm{OH}$. 


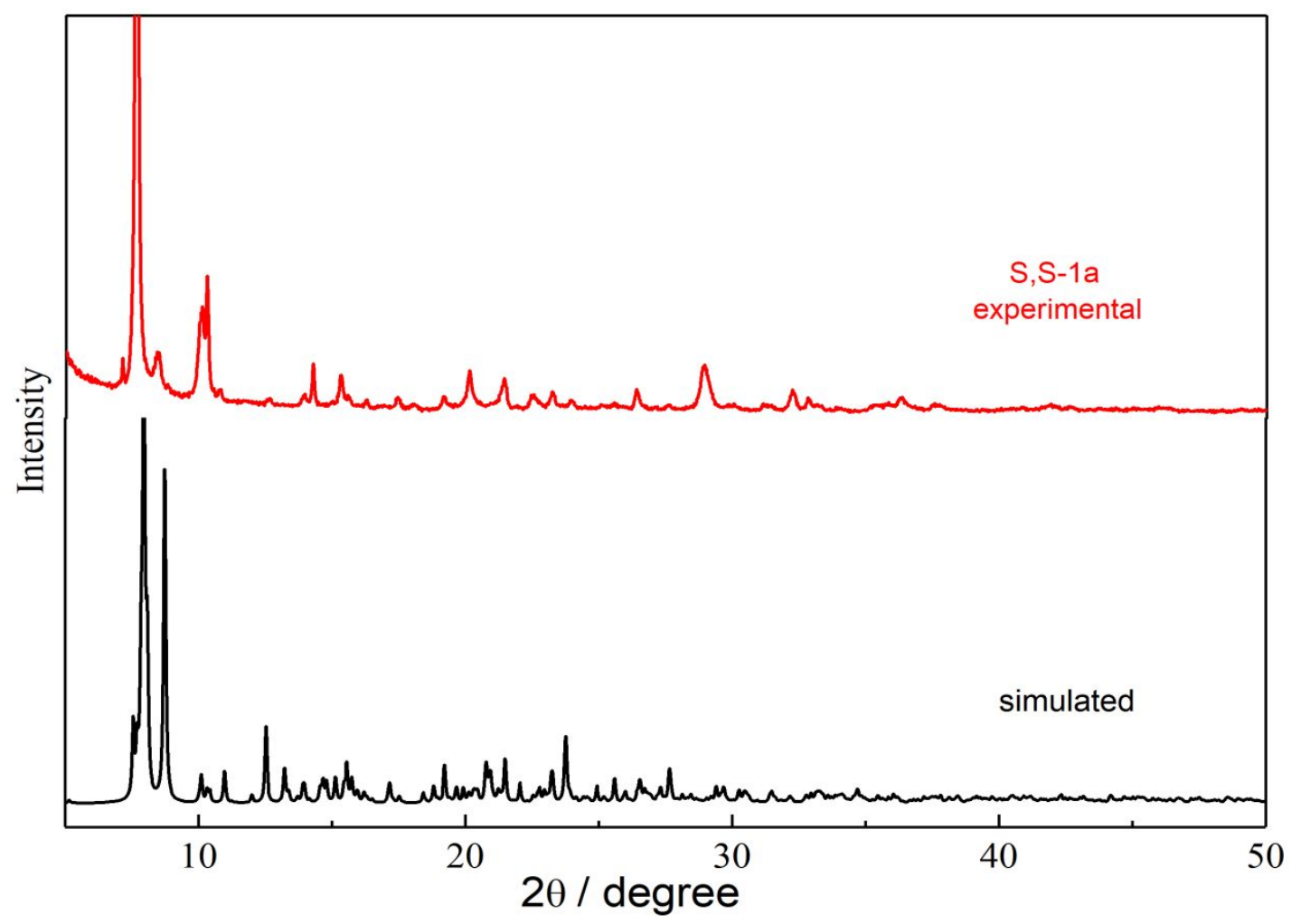

Figure SI11. PXRD patterns of Cd(II) complex $S, S-1 \mathbf{a}$.

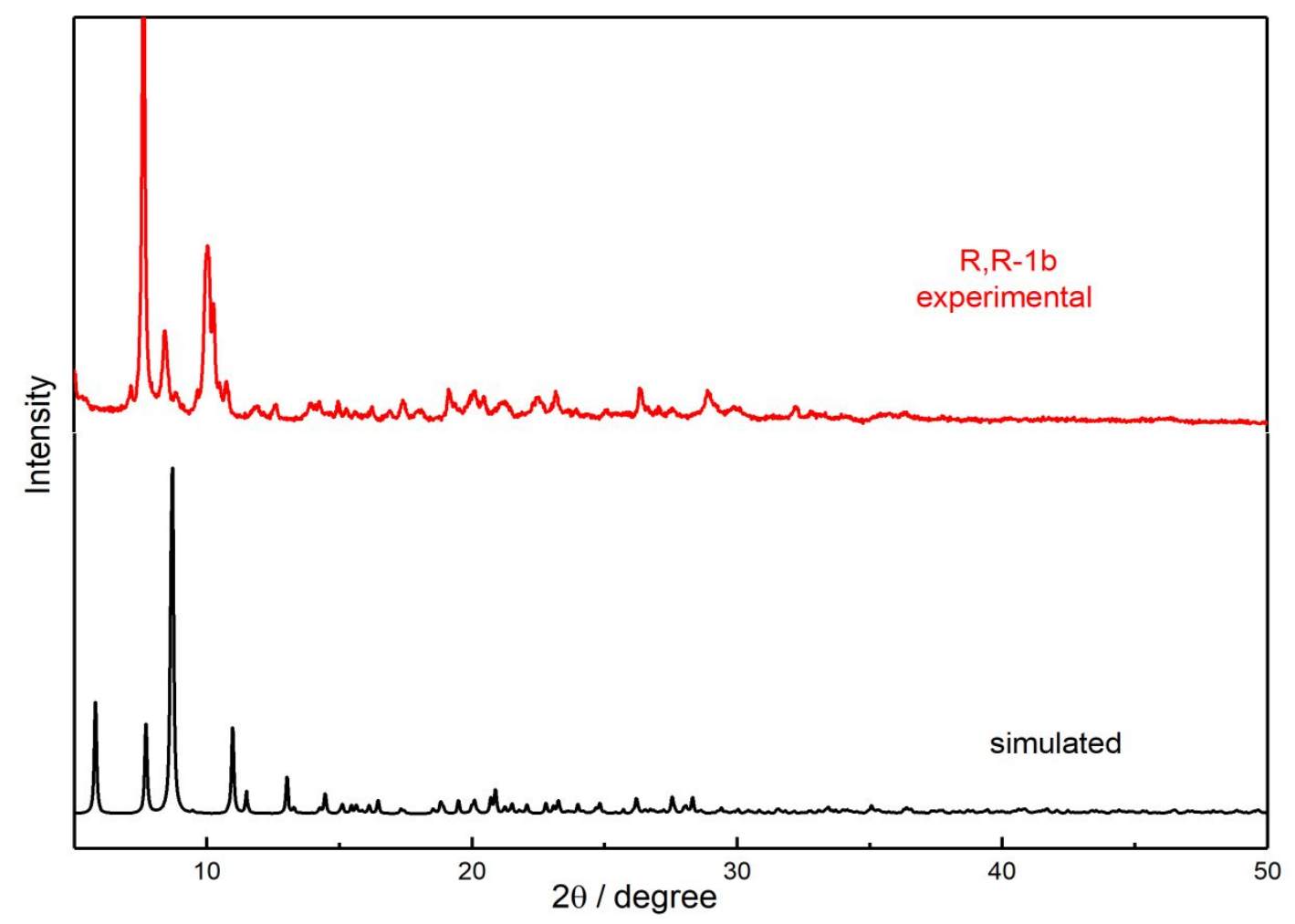

Figure SI12. PXRD patterns of Cd(II) complex $R, R-\mathbf{1 b}$. 


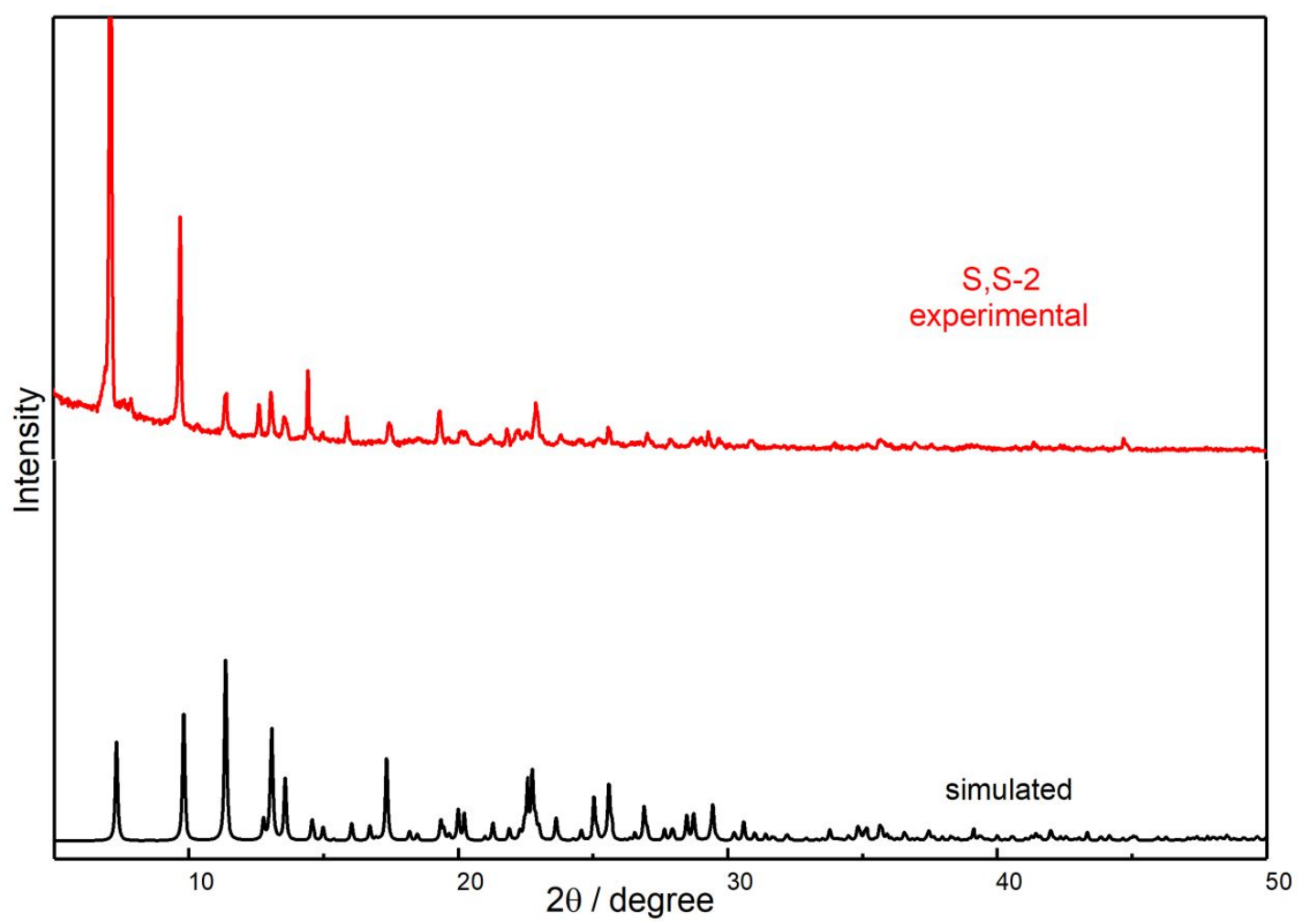

Figure SI13. PXRD patterns of $\mathrm{Cu}(\mathrm{II})$ complex $S, S-\mathbf{2}$.

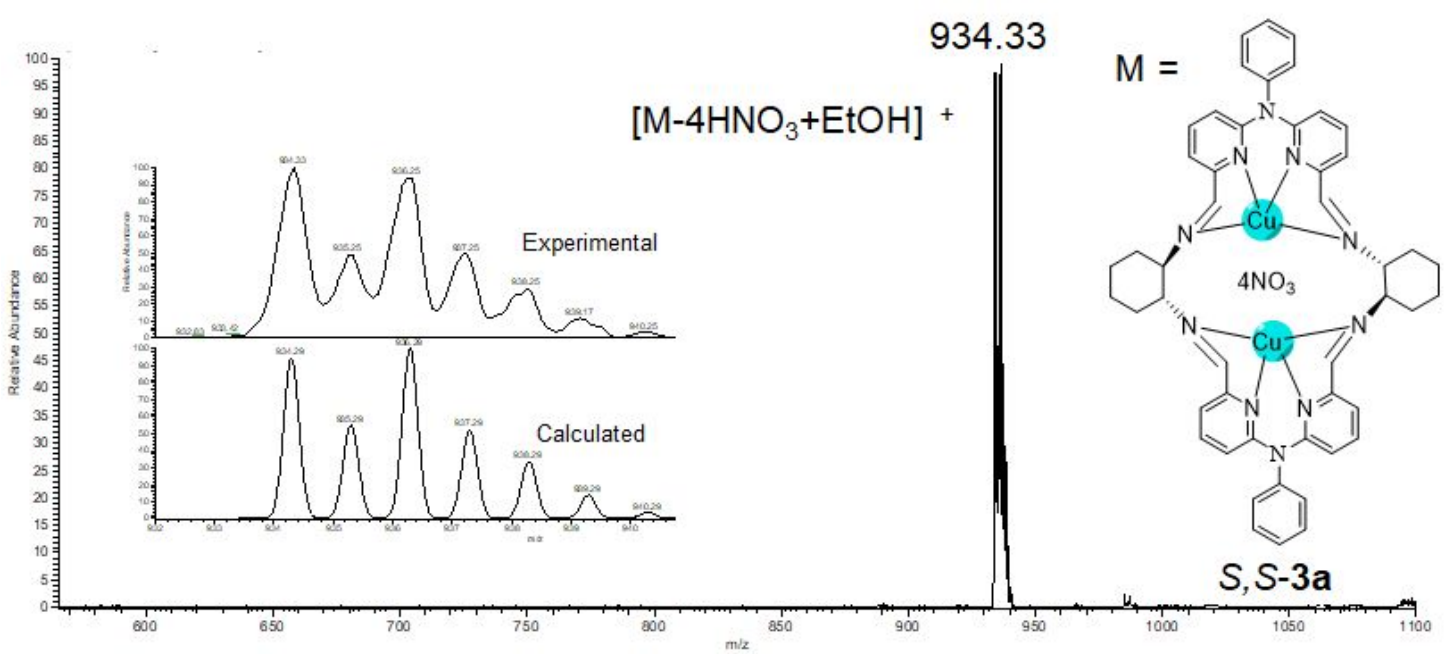

Figure SI14. ESI-MS spectrum of $\mathrm{Cu}(\mathrm{II})$ complex $S, S-3 \mathbf{a}$, together with the experimental and calculated isotopic distribution (insets) corresponding to the peak at $100 \%$ abundance for comparison. 


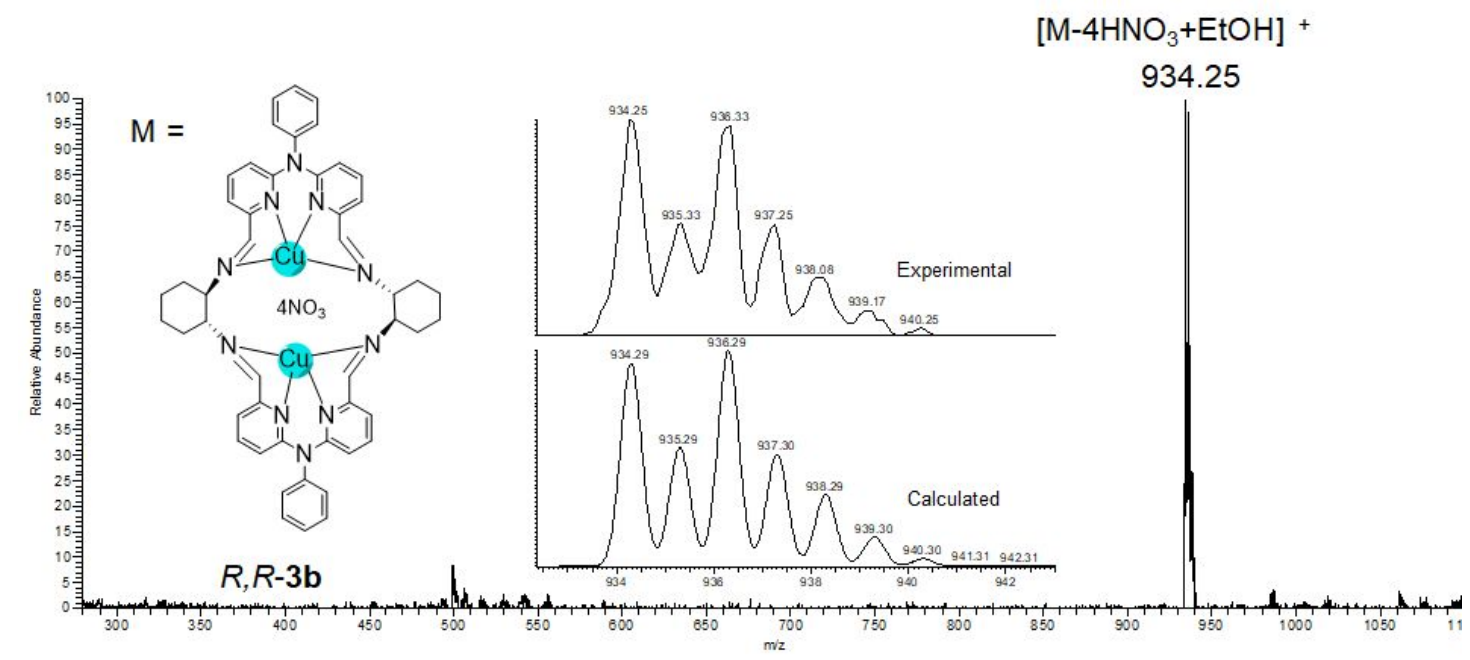

Figure SI15. ESI-MS spectrum of $\mathrm{Cu}(\mathrm{II})$ complex $R, R-\mathbf{3 b}$, together with the experimental and calculated isotopic distribution (insets) corresponding to the peak at $100 \%$ abundance for comparison.

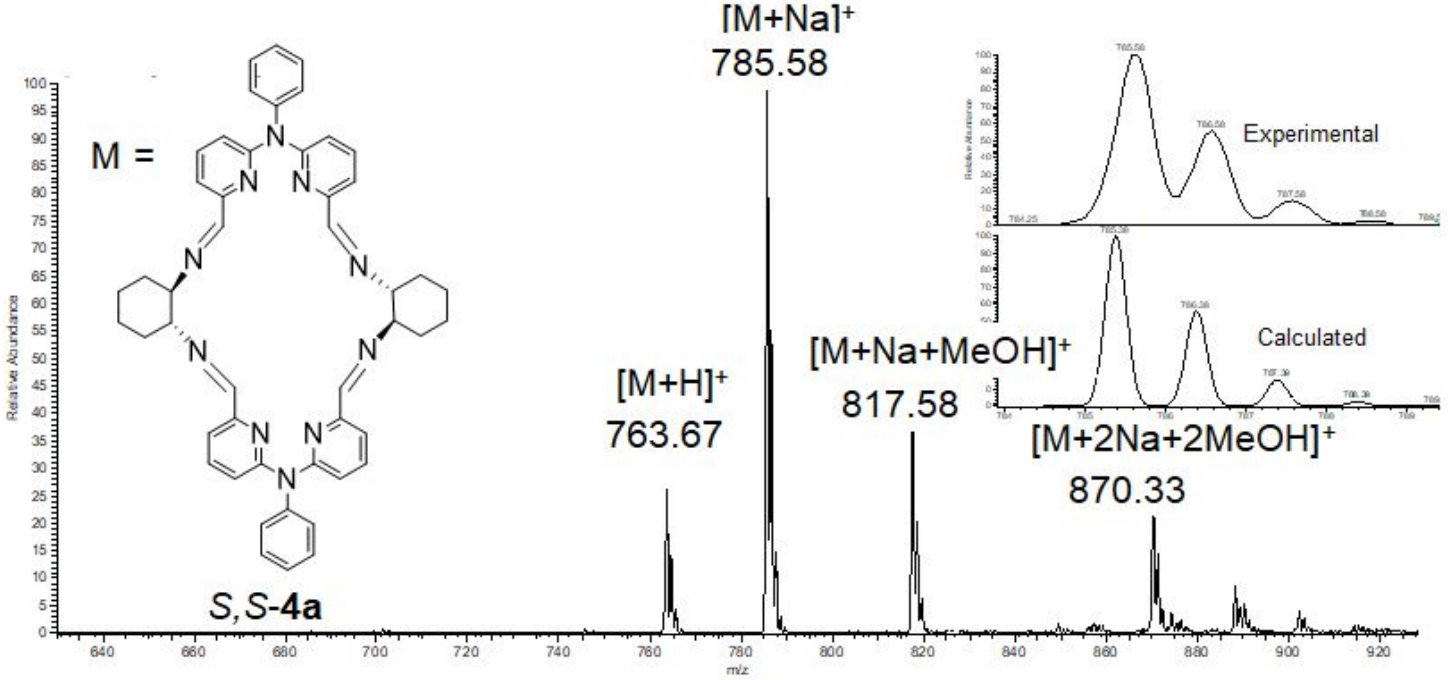

Figure SI16. ESI-MS spectrum of compound $S, S-\mathbf{4 a}$, together with the experimental and calculated isotopic distribution (insets) corresponding to the peak at $100 \%$ abundance for comparison. 


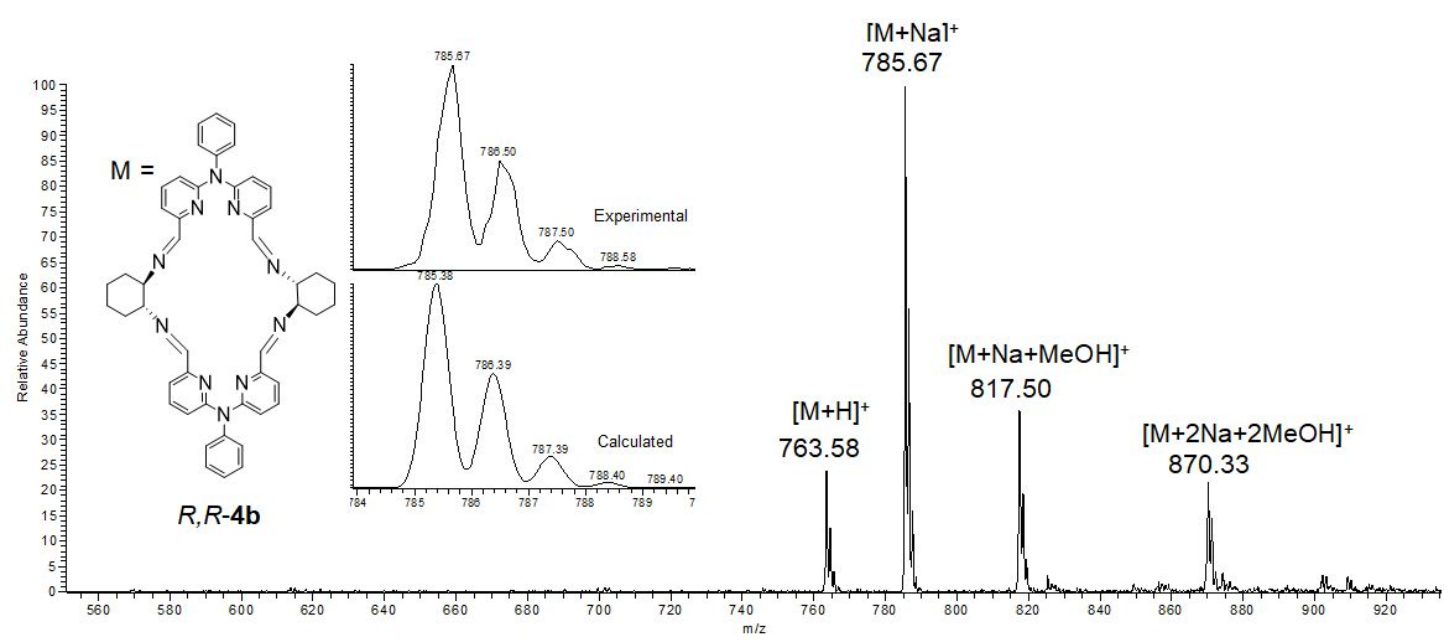

Figure SI17. ESI-MS spectrum of compound $R, R-\mathbf{4 b}$, together with the experimental and calculated isotopic distribution (insets) corresponding to the peak at $100 \%$ abundance for comparison.

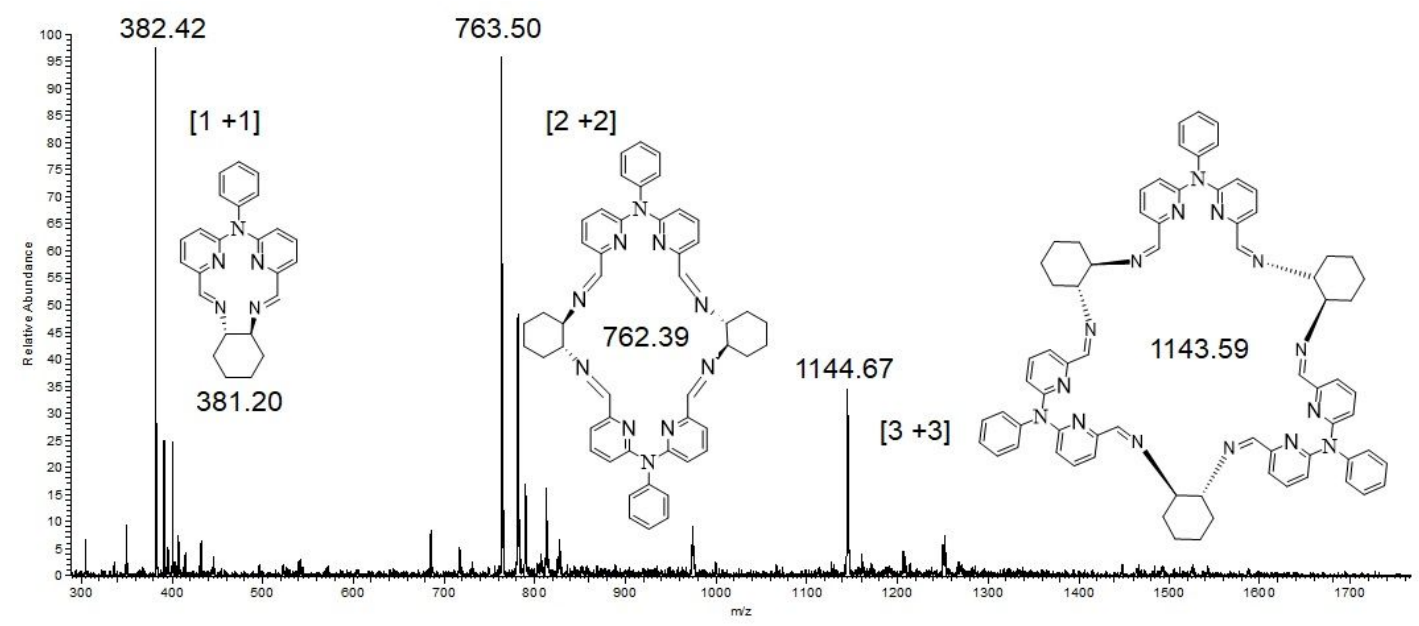

Figure SI18. ESI-MS spectrum of compound $S, S-4 \mathbf{a}$ which was directly synthesized from PDPA and S,S-DACH, together with the experimental and calculated isotopic distribution (insets) corresponding to the peak at 100\% abundance for comparison. 


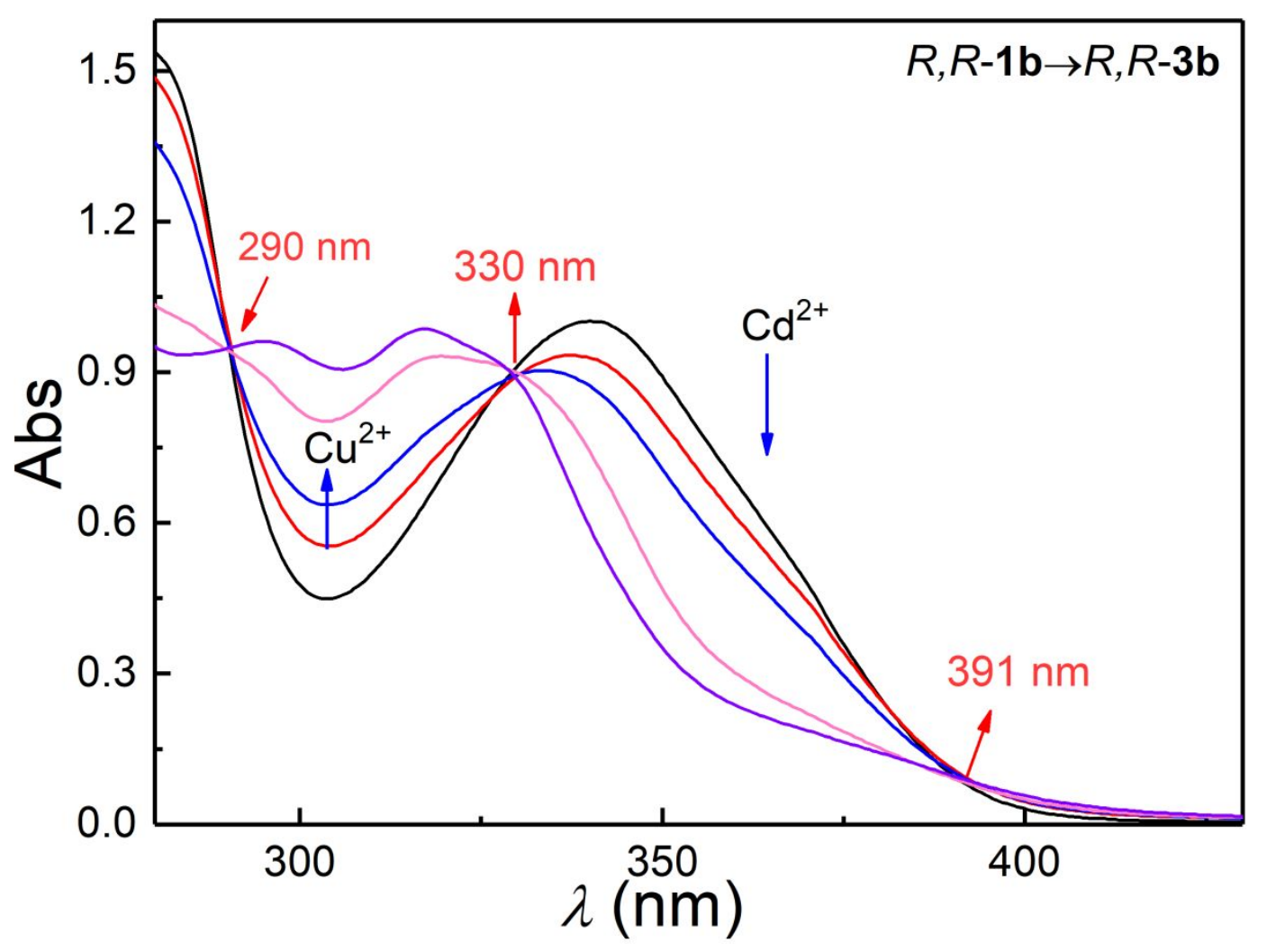

Figure SI19. UV-vis titration of $R, R-\mathbf{1 b}$ with $\mathrm{Cu}\left(\mathrm{NO}_{3}\right)_{2} \cdot 3 \mathrm{H}_{2} \mathrm{O}$ in $\mathrm{MeOH}$ at $\mathrm{RT}$.

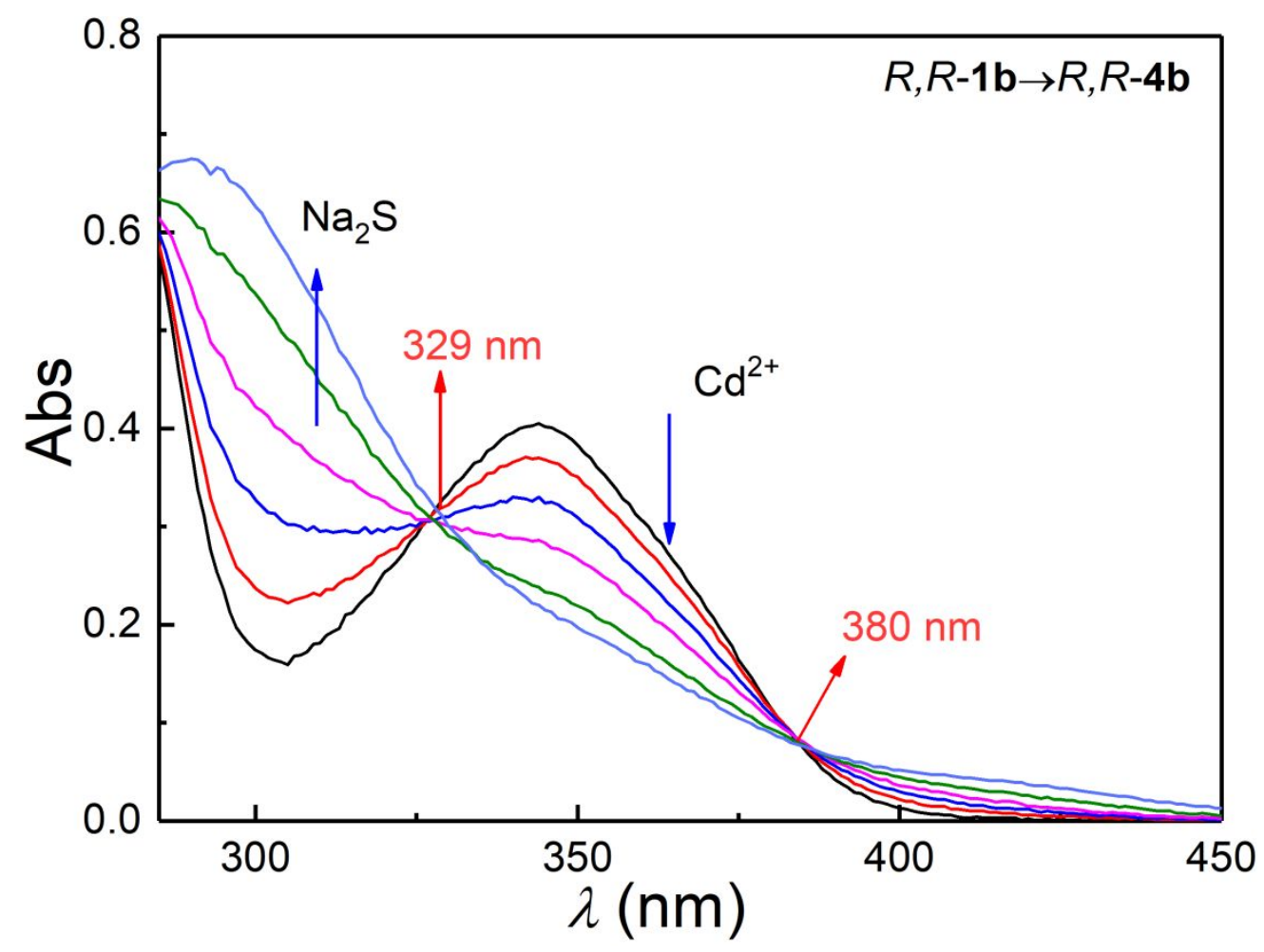

Figure SI20. UV-vis titration of $R, R-\mathbf{1 b}$ with $\mathrm{Na}_{2} \mathrm{~S}$ in $\mathrm{MeOH}$ at $\mathrm{RT}$. 


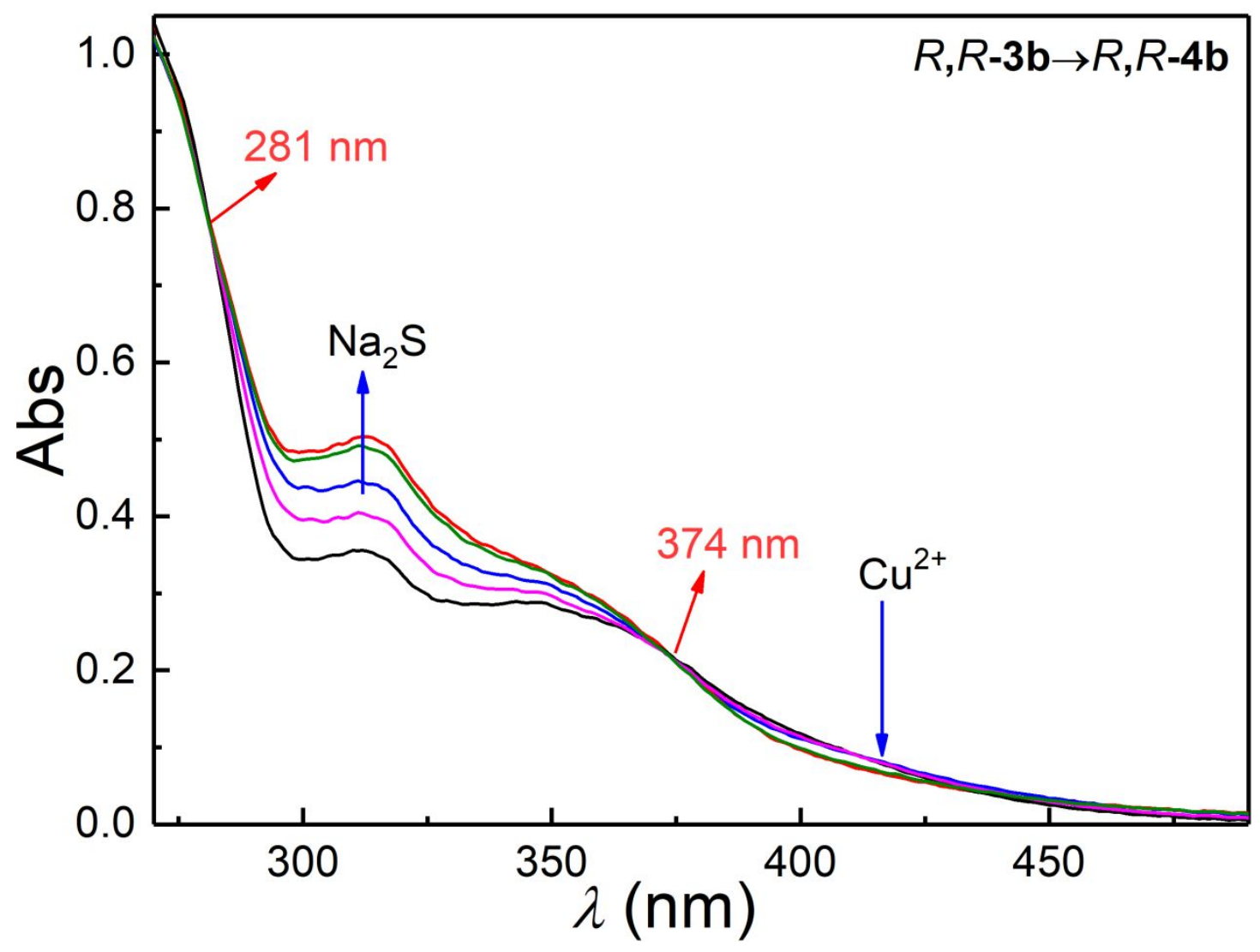

Figure SI21. UV-vis titration of $R, R-3 \mathbf{b}$ with $\mathrm{Na}_{2} \mathrm{~S}$ in $\mathrm{MeOH}$ at RT.

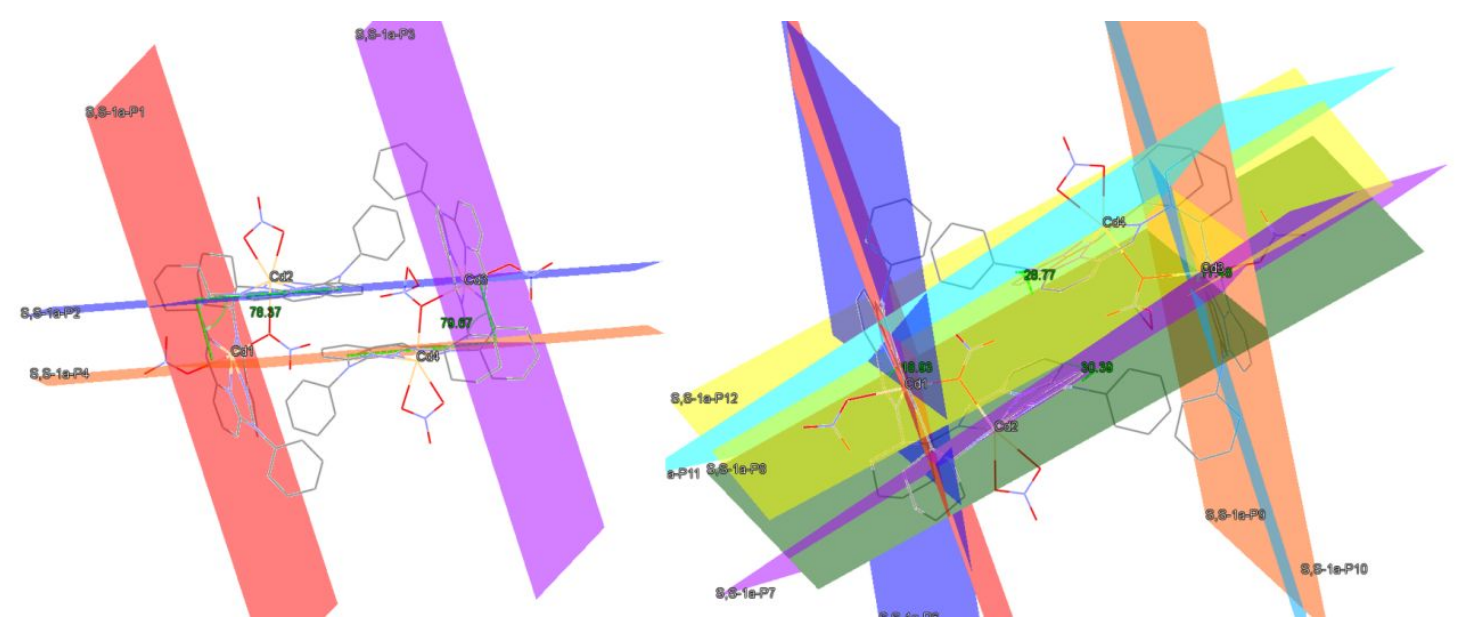

Figure SI22. Perspective view of the packing structure of complex $S, S-\mathbf{1 a}$ showing the intramolecular dihedral angles $\left(^{\circ}\right)$ between planes. 


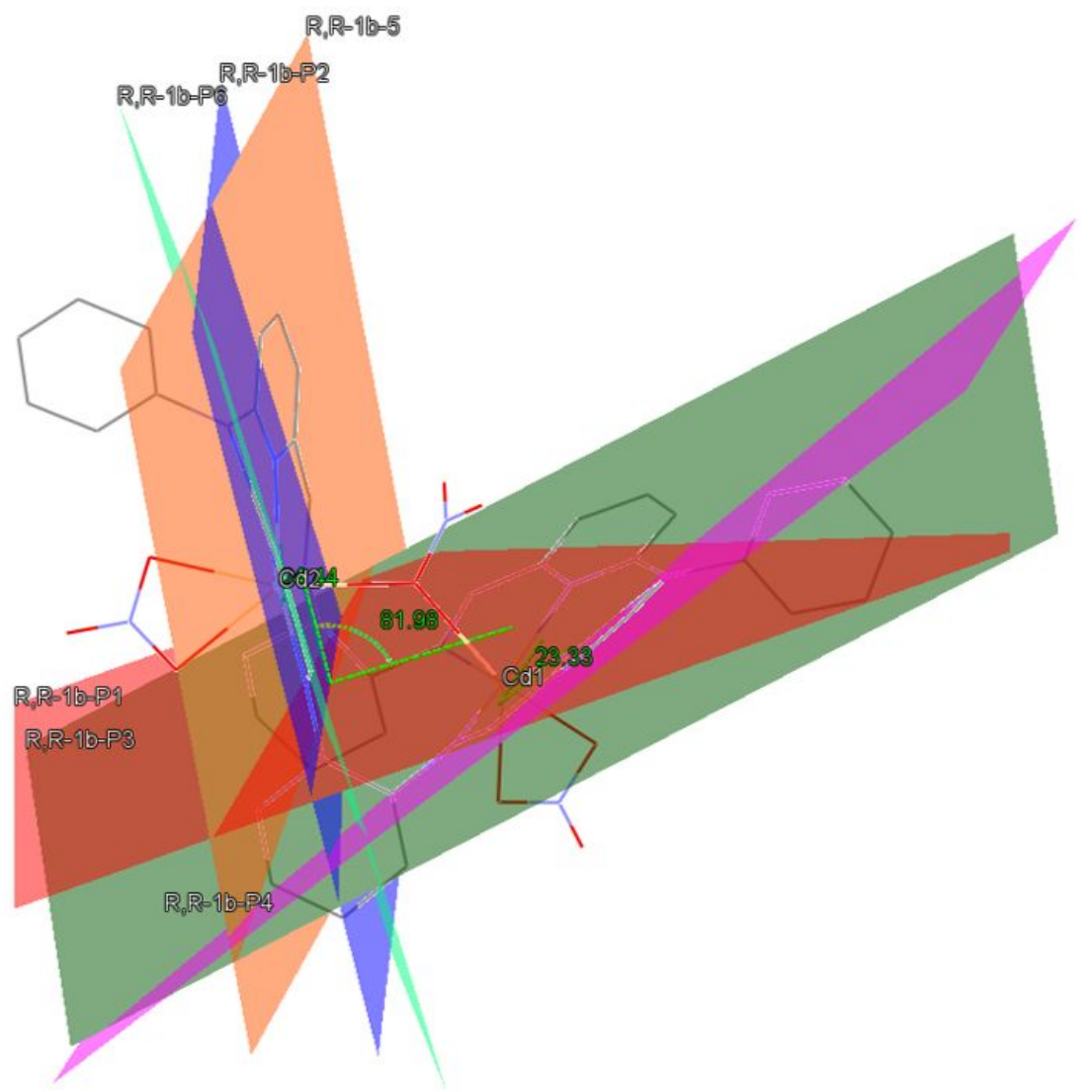

Figure SI23. Perspective view of the packing structure of complex $R, R-\mathbf{1 b}$ showing the intramolecular dihedral angles $\left(^{\circ}\right)$ between planes.

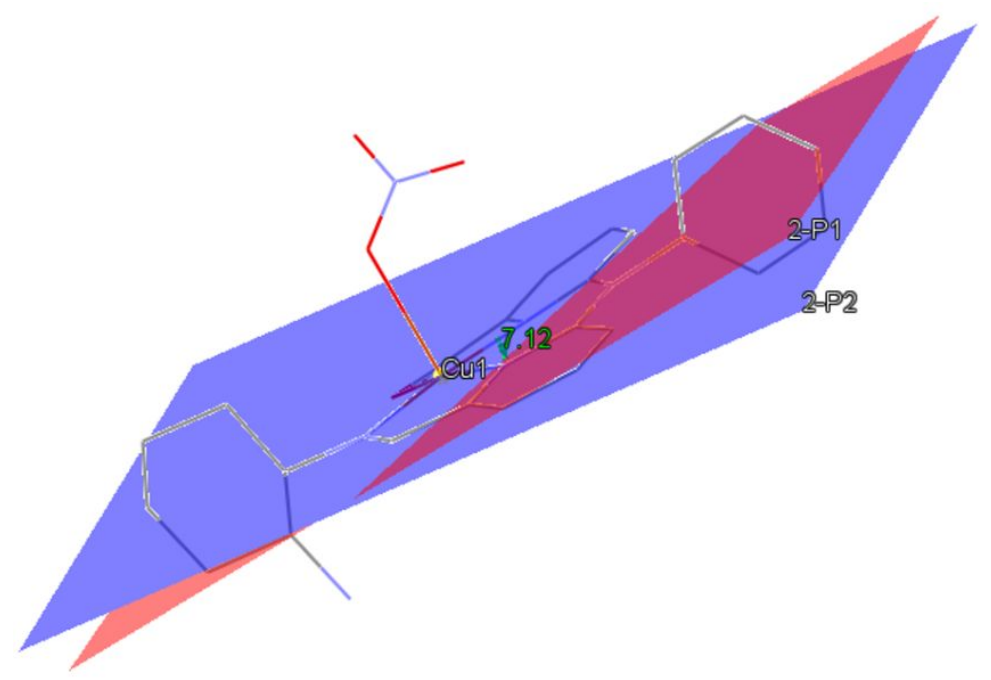

Figure SI24. Perspective view of the packing structure of complex $S, S-2$ showing the intramolecular dihedral angles $\left(^{\circ}\right)$ between planes. 